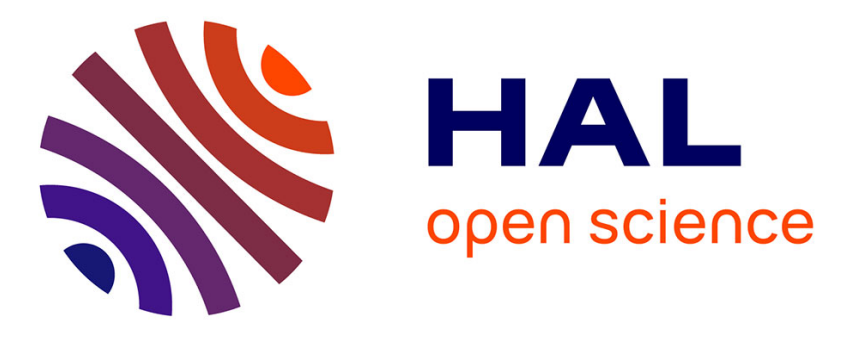

\title{
Method to approximate intra oral scanner noise and resolution
}

\author{
Alban Desoutter, Osama Yusuf Solieman, Gérard Subsol, Michel Fages, \\ Frédéric Cuisinier
}

\section{- To cite this version:}

Alban Desoutter, Osama Yusuf Solieman, Gérard Subsol, Michel Fages, Frédéric Cuisinier. Method to approximate intra oral scanner noise and resolution. Lasers in Dentistry XXV, Feb 2019, San Francisco, United States. pp.10857-6, 10.1117/12.2509460 . lirmm-02084852

\section{HAL Id: lirmm-02084852 https://hal-lirmm.ccsd.cnrs.fr/lirmm-02084852}

Submitted on 18 Apr 2019

HAL is a multi-disciplinary open access archive for the deposit and dissemination of scientific research documents, whether they are published or not. The documents may come from teaching and research institutions in France or abroad, or from public or private research centers.
L'archive ouverte pluridisciplinaire HAL, est destinée au dépôt et à la diffusion de documents scientifiques de niveau recherche, publiés ou non, émanant des établissements d'enseignement et de recherche français ou étrangers, des laboratoires publics ou privés. 


\title{
Method to approximate intra oral scanner noise and resolution
}

\author{
A. Desoutter ${ }^{1}$, O. Yusuf Solieman ${ }^{1}$, G. Subsol' ${ }^{2}$, M. Fages ${ }^{1}$, F. Cuisinier ${ }^{1}$ \\ ${ }^{1}$ LBN, Univ. Montpellier (France) \\ ${ }^{2}$ Project-Team ICAR, LIRMM, CNRS, Univ. Montpellier (France)
}

Author names and affiliations:

- Alban Desoutter, LBN, Univ. Montpellier, 545 avenue professeur Jean-Louis Viala, 34193

Montpellier Cedex 5. Mail: alban.desoutter@umontpellier.fr

- Osama Yusuf Solieman, LBN, Univ. Montpellier, 545 avenue professeur Jean-Louis Viala, 34193 Montpellier Cedex 5. Mail: dr.osyusuf@gmail.com

- Gérard Subsol, LIRMM, Campus St Priest, 161 Rue Ada, 34090 Montpellier (France). Mail: gerard.subsol@lirmm.fr

- Michel Fages, LBN, Univ. Montpellier, 545 avenue professeur Jean-Louis Viala, 34193 Montpellier Cedex 5. Mail: michel.fages@univ-montp1.fr

- Frédéric Cuisinier, LBN, Univ. Montpellier, 545 avenue professeur Jean-Louis Viala, 34193 Montpellier Cedex 5. Mail: frederic.cuisinier@umontpellier.fr

* Corresponding author:

E-mail: alban.desoutter@umontpellier.fr

\begin{abstract}
In dentistry, 3D intra-oral scanners (IOS) are gaining increasing popularity essentially for the production of dental prostheses. Until now, there is no normalized procedure to evaluate the resolution of intra-oral scanners. Such procedure could a positive parameter for the IOS market and a first step in the normalization of the market.

The aim of this study is to present a reproducible methodology to estimate the noise and resolution of any IOS. For the noise, we use two IOS: Trios 2 (3Shape) and Carestream 3600 (Carestream) and the last one for the resolution.

We used for this, and as reference, an ultra-flat and ultra-smooth alumina. For IOS, such object should be perfectly flat, and all roughness recorded considered as noise.

In this study the root mean square (RMS) values obtained are comprised between 5.29 and 12.58 micrometers, but significant differences have been found between central part and the whole mesh. This is due to edge effect: deviation from flat surface is more important on the edge of meshes than internal part.

To evaluate resolution, a ceramic tip, well-polished was recorded with IOS and compare to the mesh obtain with micro tomography ( 5 micrometer resolution). We measured the distance between the two plans of the tip, considered as the small detail recorded. We find a distance of 25 micrometers and from 89 to 121 micrometers with IOS studied.

Such method could be perfectly suitable to evaluate and compare commercial IOS.
\end{abstract}

Key-word: intra oral scanner, noise, resolution, micro CT, mesh.

\section{Introduction}

Since 30 years and his creation ${ }^{1}$, CAD-CAM (computer-aided design and computer-aided manufacturing) are more and more present in dentistry and compete conventional polymer material techniques in dental offices. The intra oral scanner permit to realized prosthesis by machining or rapid prototyping in a single visit for the patient. They provide a three-dimensional mesh calculated by a software. Then, the practitioner design a 
virtual prosthesis to be fabricated by machining or rapid prototyping. They are medical devices subject to strict regulations.

To allow optimum acquisition by avoiding light reflection and transparency, powder system with $\mathrm{TiO}_{2}$ nanoparticles were used. Nowadays, new intra-oral scanners are actually powder free ${ }^{2}$.

Error of measurement and the impact of deviation from ideal angulation of intra-oral scanners were studied ${ }^{3}$, but with the whole CAD-CAM system including the production unit, which was also investigated ${ }^{4}$. Another study, in 2000, evaluate the effect of operator-controlled camera misalignment on restoration adaptation ${ }^{5}$.

But from now, there is no normalized method to evaluate performance of commercial IOS. Some studies use registration of 3D images from high performance scanner and IOS to compare them and evaluate accuracy and trueness ${ }^{6}$. But noise induces and, most important, resolution of IOS were not established.

Our works try to establish a clear, simple and repeatable method to evaluate noise and resolution of the camera.

Noise is a relevant parameter for estimate the performance of IOS, which. To validate this methodology, the performances of the two IOS are evaluated by determining their noise. Two powder free IOS were evaluate for the noise part of our work: CS 3500 (Carestream, Rochester, USA) and the Trios (3shape, Copenhagen, Denmark). Blank test was realized with an ultra-flat and smoothed alumina wafer, recorded with the IOS. Noise was evaluated with RMS (root mean square) roughness.

Then, resolution was approach by an original method: a piece of ceramic was polished to create a tip, very thin at the top. We used the 3600CS (Carestream, New York State, USA) IOS as a classical and commercially available IOS. The reference method used to obtained meshes of our object is microtomography (EasyTom $150 \mathrm{kV}$, Chavanod, France) and a precision measurement machine (Microvu Excel 502, Mircrovu, Windsor, California). Those values are comparing to the measure obtained with optical measuring machine on the tip profile.

\section{Material and method}

\subsection{Material}

\subsubsection{Alumina Wafer}

For noise evaluation, wafer used in the present study is a white square $99.6 \%$ alumina wafer made by the Optics Concept Company (Paris, France). Flatness indicated is lambda/2, corresponding to a maximum wafer peak to valley length, and controlled by a Fizeau interferometer.

\subsubsection{Ceramic tip}

Feldspathic ceramic Vita Mark II block were sectioned by using high-speed diamond saw (Isomet 2000, Buehler, USA) longitudinally to have a $4 \mathrm{~cm}$ matches-like specimen. The cutting face were polished with abrasive discs up to 1200 grit and followed by polishing with diamond pastes of 0.25 and $0.1 \mu \mathrm{m}$ particle size using a polishing machine (Escil, France).

\subsubsection{Micro Computed Tomography (micro CT)}

Tomography of the tip was recorded with an EasyTom $150 \mathrm{kV}$ system (RX Solution, Chavanod, France). X ray source was $70 \mathrm{kV}$ voltage, voxel size was 5.4 micrometer and an aluminum filter was placed front of the $\mathrm{X}$ ray generator. 


\subsubsection{Optical measuring machine}

The Excel 502 Multisensor Measuring machine provides high speed and accuracy measurements. The Excel $502 \mathrm{UM} / \mathrm{UC}$ (Windsor, California 95492, USA) allows measurement of 400x500x250 mm specimen with XY Accuracy of $2.8+\mathrm{L} / 200$, a $\mathrm{Z}$ accuracy of $3.0+\mathrm{L} / 100$ and a scale resolution of 0.1 micrometer.

\subsection{5 atomic force microscope (AFM)}

Flatness of the wafer was attested with an AFM Nanoscope 3A Quadrex (Bruker instruments, Billerica, USA). A $30 * 30 \mu \mathrm{m}$ image was recorded in tapping mode. The soft Gwyddion v.2.43 (Czech Metrology Institute, Prague, Czech Republic) performed the RMS roughness calculation.

\subsubsection{IOS}

In our works, two IOS was studied: CS3500 intra-oral scanner from Carestream (Rochester, New York State, USA) and Trios 2 Pod (3Shape, Copenhagen, Denmark). Both are powder free systems.

\subsection{Method}

\subsubsection{Roughness RMS of wafer}

In this study, we assume that roughness RMS calculate on 3D images of the wafer recorded by IOS is the noise of the system. Calculations on meshes were realized with CloudCompare v2.6.0 software (Research and Development Institute of Electricité De France EDF, Paris, France).

\subsubsection{Roughness RMS of mesh recorded by camera}

Each camera (Trios 2 and CS3600) scanned the wafer with 3 angulations (0, 30 and 45 degrees) and two different orientations. Each time, 10 scans were recorded to verify reproducibility of manip. To calculate the noise, RMS of mesh was calculating through the distance from each vertex to the mean plan, formed by the whole mesh. Coordinates of vertices and distances from vertices to the virtual plan were exported into Excel (Microsoft, Redmond, USA) files. RMS is calculated with the equation:

$$
R_{q}=\sqrt{\frac{1}{n}\left(x_{1}^{2}+x_{2}^{2}+x_{3}^{2}+\cdots+x_{n}^{2}\right)}
$$

\subsubsection{Resolution of camera}

We assume that the resolution of IOS is the distance between the points localized at the edge of the two plans which formed the tip. No trivial method exists to select automatically vertex before curvature, on the edge of the tip. Distances were calculated with the Meshlab software tool, by selection of vertex of interest. To avoid error by manipulator, 30 measures were collected for each 3D images, and means and standard deviations were calculated. This was done both on meshes reconstructed with Micro CT and with IOS.

To confirm those results, tip curvature of the top of the tip using Meshlab Software (ISTI, Italian National Research Council, Italia).

\subsubsection{Statistical test}


Every result, to evaluate noise and resolution, was tested with current ANOVA one way test, realised with Sigmaplot v. 11.0 (Systat Software Inc, San Jose, USA).

\section{Result and discussion}

\subsection{Noise}

The RMS calculated on the $900 \mu \mathrm{m}^{2}$ surface is $17.52 \mathrm{~nm}$ with AFM (Fig $1 \mathrm{~A}$ ). The RMS values are calculated from meshes from intra-oral scanners. RMS values for the whole meshes varied between 5.29 (SD \pm 0.82 ) and 10.68 (SD \pm 0.92 ) micrometres for $\mathrm{CS} 3500$ and between $6.79(\mathrm{SD} \pm 1.56)$ and $12.58(\mathrm{SD} \pm 4.95)$ micrometres for Trios. Figure $1 \mathrm{~B}$ and $\mathrm{C}$ represent examples of 3D meshes coloured with a look-up table corresponding to the vertices-to-virtual plan distance.

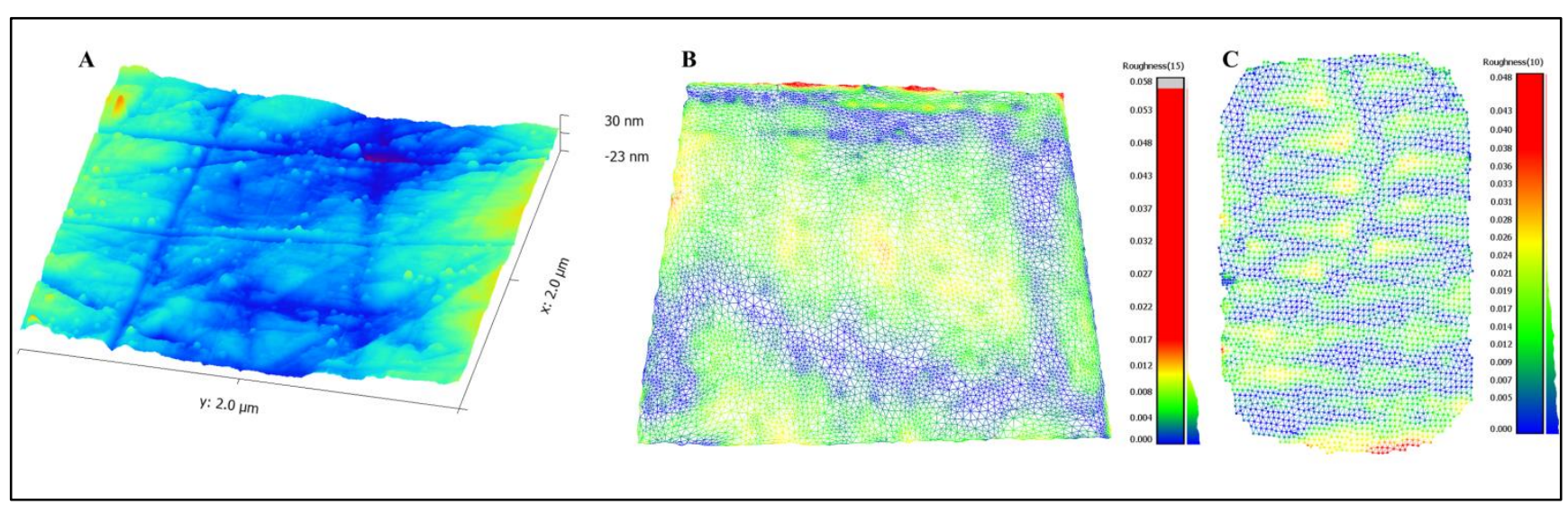

Figure 1

A) wafer scanned with AFM ; B) mesh of wafer scanned with Trios ; C) mesh wafer scanned with Carestream CS3600 IOS

As we can see on images in Fig 1, noise is more important on the edge of mesh scanned with IOS. Indeed, for the whole mesh, we found a RMS roughness statistically most important than for the central part of the same mesh, as we can see in Table I.

\section{Table I}

RMS results for CS3500 and Trios IOS. Superscripts letters indicate whether there was a significant difference.

\begin{tabular}{|c|c|c|c|c|c|c|c|c|c|c|c|c|c|}
\hline & & \multicolumn{2}{|c|}{0 (a) } & \multicolumn{2}{|c|}{30.1 (b) } & \multicolumn{2}{|c|}{30.2 (c) } & \multicolumn{2}{|c|}{45.1 (d) } & \multicolumn{2}{|c|}{$45.2(\mathrm{e})$} & \multicolumn{2}{|c|}{ Total } \\
\hline & & Whole & $\begin{array}{c}\text { Central } \\
\text { part }\end{array}$ & Whole & $\begin{array}{c}\text { Central } \\
\text { part }\end{array}$ & Whole & $\begin{array}{c}\text { Central } \\
\text { part }\end{array}$ & Whole & $\begin{array}{c}\text { Central } \\
\text { part }\end{array}$ & Whole & $\begin{array}{c}\text { Central } \\
\text { part }\end{array}$ & Whole & $\begin{array}{c}\text { Central } \\
\text { part }\end{array}$ \\
\hline Carest & $\operatorname{RMS}(\mu \mathrm{m})$ & $7.54^{\mathrm{b}, \mathrm{c}}$ & 5.85 & $10.68^{a, d}$ & 7.24 & $8.80^{d}$ & 7.29 & $5.29^{\mathrm{a}, \mathrm{b}, \mathrm{c}}$ & 4.36 & $7.74^{b}$ & 6.16 & 8.01 & 6.18 \\
\hline Trios & RMS $(\mu \mathrm{m})$ & $6.79^{c, e}$ & 2.91 & $7.89^{c}$ & 4.26 & $9.87^{\mathrm{a}, \mathrm{b}}$ & 3.08 & $7.22^{\mathrm{e}}$ & 1.77 & $12.58^{a, d}$ & 2.15 & 8.86 & 2.83 \\
\hline
\end{tabular}


Values of RMS roughness in the center of scanned zone indicate the IOS have a low ratio signal on noise (RSN). But the impact of edge effect on a reconstruction of teeth in current practice could be a problem. Further investigation must be realized to estimate such impact.

\subsection{Resolution}

The profile of the tip, recorded with optical measurement machine, gives an idea of the reality of the $2 \mathrm{D}$ profile of the tip, as represent on Fig 2-A.

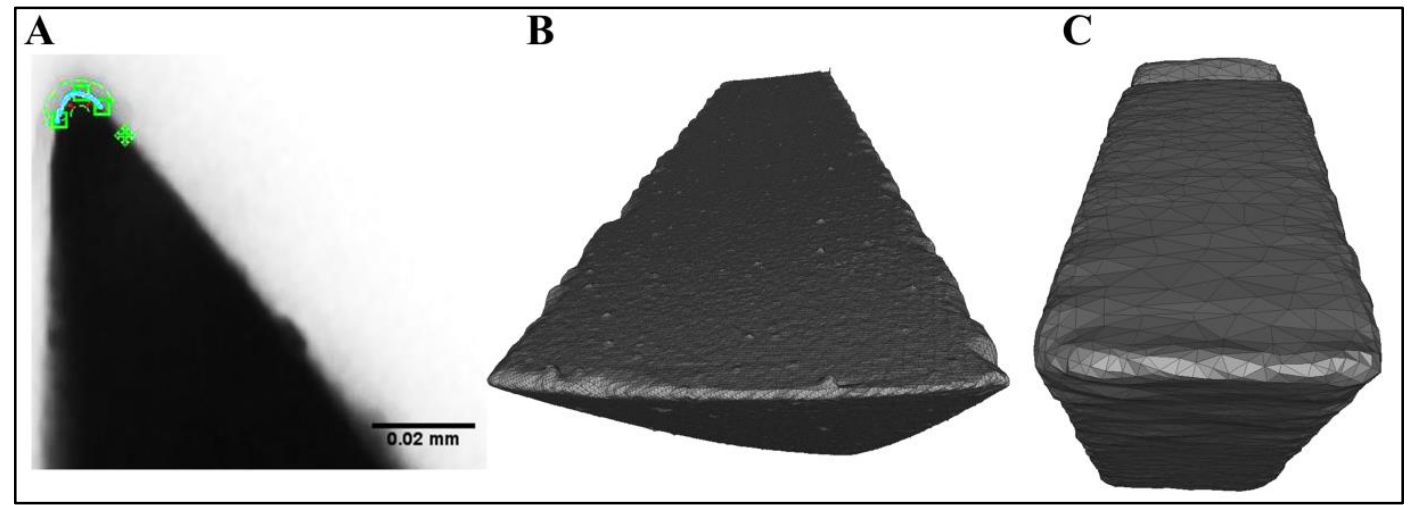

Figure 2

A) profile tip recorded B) mesh of the tip reconstructed with Micro CT C) mesh of the tip scanned with CS3600 IOS

The distance between the two plans of the tip is 8.7 and 18.6 micrometers. With our method, we found a distance of 25.98 micrometers for the mesh reconstruct with micro CT, and around hundred micrometers with CS3600 IOS, as report in Table 2.

Table 2

Distance measured between two plans of the tip calculated with Micro CT mesh (a) and with IOS (b to f)

\begin{tabular}{|c|c|c|c|c|c|c|}
\hline & a. Micro CT & b. Cam test 1 & c. Cam test 2 & d. Cam test 3 & e. Cam test 4 & f. Cam test 5 \\
\hline Mean $(\mu \mathrm{m})$ & $25.98^{b, c, d, e, f}$ & $121.22^{\mathrm{a}, \mathrm{d}, \mathrm{f}}$ & $110.61^{\mathrm{a}}$ & $89.67^{a, b, e}$ & $124.28^{\mathrm{a}, \mathrm{d}}$ & $91.67^{a, b}$ \\
\hline $\mathrm{SD}(\mu \mathrm{m})$ & 7.10 & 20.85 & 22.70 & 14.19 & 31.18 & 25.03 \\
\hline Median $(\mu \mathrm{m})$ & 24.50 & 118.50 & 109.50 & 89.50 & 124.50 & 86.00 \\
\hline
\end{tabular}

We note that from one scan to another, values could vary from $\sim 90$ to $\sim 120$ micrometers. The reproducibility is not optimal, while it was the same person, a specialist of CAD CAM, in the same condition, who realized the gesture. Moreover, those values do not mean that the IOS does not see anything from, but we not that the soft create a mean value from all shots. Number of images needed to reconstruct such an object is variable and could be count as decade. So the software may play a role in the reduction of a high angulation and smooth it. The result is could be a loss of information. 


\section{Conclusion}

Our work highlights the important performance of IOS. The two methods used here to determine noise and system resolution could be standardized and automated to make comparisons between IOS, and help practitioners in choosing the best system. Regarding noise, it seems that it does not play an important role, which shows the good performance of IOS. However, the poor camera results studied are an indication of a significant loss of information, especially on abrupt surface changes, as is the case with a tip.

\section{Acknowledgements}

We acknowledge the MRI platform of the national infrastructure France-BioImaging supported by the French National Research Agency (ANR-10-INBS-04, «Investments for the future»), the labex CEMEB (ANR-10LABX-0004) and NUMEV (ANR-10-LABX-0020).

We acknowledge Michel Ramonda, research engineer at CTM - Montpellier University, for AFM imaging.

[1] Duret, F. and Termoz, C., "Method of and apparatus for making a prosthesis, especially a dental prosthesis" (1987).

[2] Li, H., Lyu, P., Wang, Y. and Sun, Y., "Influence of object translucency on the scanning accuracy of a powder-free intraoral scanner: A laboratory study," The Journal of prosthetic dentistry 117(1), 93-101 (2017).

[3] Parsell, D. E., Anderson, B. C., Livingston, H. M., Rudd, J. I. and Tankersley, J. D., "Effect of camera angulation on adaptation of CAD/CAM restorations," Journal of Esthetic and Restorative Dentistry 12(2), 78-84 (2000).

[4] Lilja, M. and Oberg, T., "Volumetric determinations with CAD/CAM in prosthetics and orthotics: errors of measurement," Journal of rehabilitation research and development 32(2), 141 (1995).

[5] Parsell, D. E., Anderson, B. C., Livingston, H. M., Rudd, J. I. and Tankersley, J. D., "Effect of camera angulation on adaptation of CAD/CAM restorations," Journal of Esthetic and Restorative Dentistry 12(2), 78-84 (2000).

[6] Patzelt, S. B., Emmanouilidi, A., Stampf, S., Strub, J. R. and Att, W., “Accuracy of full-arch scans using intraoral scanners," Clinical oral investigations 18(6), 1687-1694 (2014). 